\title{
Thermal Properties of Shape-Stabilized Phase Change Materials Based on Porous Supports for Thermal Energy Storage
}

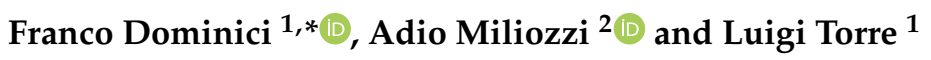 \\ 1 Civil and Environmental Engineering Department, Unità di Ricerca Consorzio Interuniversitario per la Scienza \\ e la Tecnologia dei Materiali (INSTM), University of Perugia, 05100 Terni, Italy; luigi.torre@unipg.it \\ 2 Italian National Agency for New Technology, Energy and Sustainable Development (ENEA), \\ 00123 Rome, Italy; adio.miliozzi@enea.it \\ * Correspondence: franco.dominici@unipg.it
}

check for updates

Citation: Dominici, F.; Miliozzi, A.; Torre, L. Thermal Properties of Shape-Stabilized Phase Change Materials Based on Porous Supports for Thermal Energy Storage. Energies 2021, 14, 7151. https://doi.org/ 10.3390/en14217151

Academic Editor: Anna Castaldo

Received: 26 September 2021

Accepted: 21 October 2021

Published: 1 November 2021

Publisher's Note: MDPI stays neutral with regard to jurisdictional claims in published maps and institutional affiliations.

Copyright: (c) 2021 by the authors. Licensee MDPI, Basel, Switzerland. This article is an open access article distributed under the terms and conditions of the Creative Commons Attribution (CC BY) license (https:// creativecommons.org/licenses/by/ $4.0 /)$.

\begin{abstract}
The use of phase change materials (PCM) for thermal energy storage (TES) is of great relevance, especially for the exploitation, in various ways, of the major ecological resource offered by solar energy. Unfortunately, the transition to the liquid state of PCM requires complex systems and limits their application. The goal of producing shape-stabilized phase change materials (SSPCM) is mainly pursued with the use of media capable of containing PCM during solid/liquid cycles. In this work, four cheap shape stabilizers were considered: sepiolite, diatomite, palygorskite and zeolite and two molten salts as PCM, for medium (MT) and high temperature (HT). The SSPCM, produced with an energy saving method, showed good stability and thermal storage performances. Diatomite reaches up to $400 \%$ wt. of encapsulated PCM, with a shape stabilization coefficient $\left(\mathrm{SS}_{\mathrm{c}}\right)$ of $97.7 \%$. Zeolite exhibits a $\mathrm{SS}_{\mathrm{c}}$ of $87.3 \%$ with $348 \%$ wt. of HT-PCM. Sepiolite contains $330 \%$ wt. of MT-PCM with an $\mathrm{SS}_{\mathrm{c}}$ of 82.7 . Therefore, these materials show characteristics such that they can be efficiently used in thermal energy storage systems, both individually and inserted in a suitable matrix (for example a cementitious matrix).
\end{abstract}

Keywords: shape-stabilized phase change materials SSPCM; encapsuled; diatomite; sepiolite; zeolite; molten salt; thermal energy storage TES

\section{Introduction}

To assure the containment of global warming, the reduction of greenhouse gas emissions, an environmental sustainability of human activities and a strong reduction of fossil energy resources [1-4] the use of Renewable Energy Sources (RESs) [5,6] is required. Solar energy in general, and concentrated solar energy in particular, is a RES that can play an important role in this context; in fact, it shows the advantage of large availability, cleanliness and sustainability, providing zero-emission high-temperature heat and electricity. Many ways of exploiting solar energy have been studied for the most disparate purposes $[7,8]$. The bottleneck in the use of the solar energy is linked to its intermittency and variability [9], characteristics of the main renewable sources such as photovoltaic and wind energy. It can produce a misalignment between energy supply and demand. Thermal Energy Storage (TES) is the key technology to overcome the problem of the dispatchability of the Concentrated Solar Thermal or Power plants operating at middle or high temperature [10-13]. The purpose of a TES is to store excess solar energy, in the form of sensible heat, latent heat or thermochemical energy, to supply it in subsequent instants in which it is more requested or simply paid better.

Low-cost, high efficiency Heat Storage Materials (HSM) are required for high temperature applications. Among these, Phase Change Materials (PCM), which exploit latent heat with an almost isothermal solid-liquid transition, have attracted increasing attention due to their high energy storage density [14]. PCM, used as HSM for medium-high temperature Latent Heat TES (LHTES), are mainly inorganic salts: they include nitrates, 
sulfates, carbonates and chlorine salts. They are regarded as good candidates because of their appropriate melting/freezing point, large latent heat enthalpy, excellent physical and thermal stability, and low cost a few works deal with the use [15-17]. Generally, metal, ceramics, or polymer materials are used to encapsulate the PCMs to prevent leakage during solid-liquid phase change process and to reduce the corrosion of structural materials [18-21]. Alternatively, shape-stabilized PCMs (SSPCM) can be used to maintain its solid shape, even when the solid to liquid phase change occurs, and to avoid the interactions between PCM and surrounding materials or environment, even at elevated temperatures [22,23]. Furthermore, the SSPCM allows direct contact between PCM and Heat Transfer Fluid (HTF), which is advantageous for increasing the heat exchange rate compared to traditional macro-encapsulation techniques [24]. In the SSPCMs, the capillary force and surface tension, provided by the skeleton material restrain the flow of molten salts and prevents their leakage.

There are various shape stabilization materials with high surface areas, high pore volume and good thermal and chemical stability at elevated temperatures that can be used in this application of zeolite as a shape [25]. One of the most used is the diatomite, a sedimentary rock originated from the siliceous fossilized skeletons of diatoms [26-28]. Diatomite possesses a variety of unique properties including light mass, high specific surface area, high porosity (80-90\%), excellent absorption capacity, and good thermal and chemical stability at elevated temperatures $[29,30]$. Moreover, it is abundant and at a relatively low price.

In the present work, the heat storage materials, with particular attention to composite materials consisting of a phase change material and a structural one, necessary for the stabilization of the shape, have been analyzed. These composite materials show some advantages: high energy density, good chemical and thermal stability and shape stabilization. There are various PCM that can be used to make composites with medium-high melting temperatures [31]: nitrates, chlorides, carbonates, sulfates and their combinations. The choice of shape stabilization materials is also wide: for example, diatomite, sepiolite and zeolite. A second aspect that will be considered is the adoption of an impregnation process that is energy-efficient-that is, at a low temperature [32]. This aspect is very important as it directly impacts on the costs of realization of the SSPCM and, therefore, on its possible commercialization.

In the following, a brief review on the use of sepiolite diatomite and zeolite based absorbent media as shape stabilization materials is given. Choosing an appropriate porous support and integrating it with a PCM permits to realize a SSPCM with enhanced performance $[33,34]$.

Different materials for shape stabilization and some preparation methods of SSPCMs were studied [35-37]: vermiculite [38,39] perlite [40], kaolin [41,42], expanded graphite [43,44], and many other porous media, were considered as shape stabilizers (SS). Some promising results were obtained using diatomite $[45,46]$ and sepiolite $[47,48]$ to produce SSPCM. Only a few works deal with the use of zeolite as a shape stabilizer for PCM [49,50]. To the best of our knowledge, no information has been found regarding the use of natural zeolite as a structural material for shape stabilization of PCMs.

Many preparation methods have been adopted, mainly by sintering [51] or by impregnating/encapsulating the melted PCM in the SS [29]. Jeong et al. showed that vacuum preparation of PCM/diatomite composites improves PCM shape stabilization [52]. Recently Leng et al. have proposed a method of stabilization of PCM with diatomite, improved by spray water before sintering, which has shown good results [53].

In the light of the information found in the literature, it was decided to experiment with a method of production of SSPCMs that would take into account the advantages offered by preparations in vacuum and water assisted.

In literature, few works devoted to the use of porous materials to stabilize the shape of PCMs that melt at medium and high temperatures, used in solar heating/cooling systems, solar power plants, solar steam generation and efficient use of heat from industrial waste, 
exist. In this work, a mixture of three nitrate salts ( $\mathrm{LiNaK})$ of Lithium $\left(\mathrm{LiNO}_{3} 30 \% \mathrm{wt}\right.$ ), of sodium $\left(\mathrm{NaNO}_{3} 20 \% \mathrm{wt}\right.$.) and potassium $\left(\mathrm{KNO}_{3} 50 \% \mathrm{wt}\right.$.) and a eutectic mixture (EUT) of potassium nitrate $\left(\mathrm{KNO}_{3} 54.3 \%\right.$ wt.) and sodium nitrate $\left(\mathrm{NaNO}_{3} 45.7 \%\right.$ wt.), were respectively chosen as the middle-low, and high-temperature PCMs. Sepiolite, diatomite, and zeolite were used as supporting materials to prepare the SS-PCMs with different operating temperatures. Five kinds of SSPCMs (EUT/sepiolite, EUT/diatomite, EUT/zeolite, $\mathrm{LiNaK}$ /sepiolite and $\mathrm{LiNaK} /$ diatomite) were successfully prepared and their thermal and physical characterizations were carried out with accuracy. Indeed, the latter are indispensable information for shape-stabilized PCM preparing. SSPCM were successfully produced and subsequently characterized for calorimetric and morphological aspects. The DSC analysis made it possible to evaluate the effectiveness of shape stabilization and select the best samples. The morphology corroborated the calorimetric results, also providing further explanation of the results obtained.

\section{Materials and Methods}

\subsection{Materials}

The lithium nitrate $\left(\mathrm{LiNO}_{3}\right)$, sodium nitrate $\left(\mathrm{NaNO}_{3}\right)$ and potassium nitrate $\left(\mathrm{KNO}_{3}\right)$ industrial grade, needed for production of the EUT and LiNaK mixtures, were kindly provided by the National Agency for new technologies, energy and sustainable economic development (ENEA). Two grades of sepiolite (Hydrous Magnesium Silicate) named Cimsil A35 and Cimsil A55 with bulk density, respectively, of $30-90$ and $205-315 \mathrm{~kg} / \mathrm{m}^{3}$ were kindly supplied by Tolsa (Madrid, Spain). A calcined diatomite called DIA2, characterized by a density of $200 \mathrm{~kg} / \mathrm{m}^{3}$ and a sieving residue max $6 \% \mathrm{wt}$. at $325 \mathrm{mesh}$, was purchased from DEREF (Genoa, Italy). A zeolite powder, from the mining of tecto-silicates of volcanic origin (Chabazite and Phillipsite) called Zeolite ATZ $70 \mathrm{~mm}$ (ATZ70), with sieving residue at 200 mesh Max 1\% wt., was kindly offered by ATZ Zeoliti (Comiziano, Italy). The deionized water (DIW) was produced in the laboratory of the University of Perugia (Perugia, Italy) with a suitable treatment device. The list of materials is summarized in Table 1.

Table 1. Summary list of shape stabilizers and phase change materials.

\begin{tabular}{ccc}
\hline Code & Name & Composition \\
\hline A35 & Cimsil A35 & Hydrous Magnesium Silicate \\
DIA2 & Deref DIA2 & Calcined Diatomite \\
A55 & Cimsil A55 & $\mathrm{Mg}_{4} \mathrm{Si}_{6} \mathrm{O}_{15}(\mathrm{OH})_{2} 6 \mathrm{H}_{2} \mathrm{O}$ \\
ATZ70 & Zeolite ATZ 70 mm & $\mathrm{Chabazite}_{\mathrm{Phillipsite}}$ \\
EUT & Eutectic mix $\mathrm{KNO}_{3} / \mathrm{NaNO}_{3}$ & $\mathrm{KNO}_{3} / \mathrm{NaNO}_{3} 54.3 / 45.7 \% \mathrm{wt}$. \\
$\mathrm{LiNaK}$ & Triple mix $(\mathrm{Li}-\mathrm{Na}-\mathrm{K}) \mathrm{NO}_{3}$ & $\mathrm{LiNO}_{3} / \mathrm{NaNO}_{3} / \mathrm{KNO}_{3} 30 / 20 / 50 \% \mathrm{wt}$. \\
\hline
\end{tabular}

\subsection{Synthesis of Mixtures of Salts for PCM}

The phase change salt mixtures for medium and high temperatures were produced with a low temperature method, an alternative to traditional melt mixing $\left(\mathrm{T}>370{ }^{\circ} \mathrm{C}\right)$, which allows for considerable energy savings. This method, through liquid-assisted compounding (LAC) followed by vacuum drying (VD), facilitates the subsequent preparation of the SSPCMs. The synthesis of the eutectic mixture of $\mathrm{KNO}_{3} / \mathrm{NaNO}_{3}$ with the LAC + VD method was carried out by heating a solution with $42.87 \%$ wt. to $84{ }^{\circ} \mathrm{C}$. of deionized water (DIW) to which potassium nitrate $31.03 \% \mathrm{wt}$. has been added under continuous stirring. At the complete dissolution of $\mathrm{KNO}_{3}$, sodium nitrate $26.10 \% \mathrm{wt}$. was added, stirring until a solution free of salt crystals is obtained. The saline solution, made with an excess of DIW of $25 \%$ wt. with respect to the minimum solubility of the eutectic mixture at $84{ }^{\circ} \mathrm{C}$ (Figure 1a), was used for the subsequent shape stabilization process. A part of the solution is poured into a petri dish and dried in a vacuum oven $\left(84^{\circ} \mathrm{C}-24 \mathrm{~h}\right)$ to obtain the sample of EUT salts to be characterized. Considering the curves of the distinct solubility of the salts of the three-component mixture (Figure $1 \mathrm{~b}$ ) and the trend of the $\mathrm{LiNaK} / \mathrm{H}_{2} \mathrm{O}$ phase diagrams as the temperature varies [54], the LiNaK saline solution was processed similarly to the 
EUT. In this case the formulation was produced by heating at $64{ }^{\circ} \mathrm{C} 47.35 \% \mathrm{wt}$. of DIW by adding under continuous mixing $\mathrm{KNO}_{3} 26.32 \%$ wt., then $\mathrm{NaNO}_{3} 10.53 \%$ wt. and finally $\mathrm{LiNO}_{3} 15.80 \% \mathrm{wt}$. A part of the sample was dried at $64{ }^{\circ} \mathrm{C}$ to characterize the LiNaK salts.

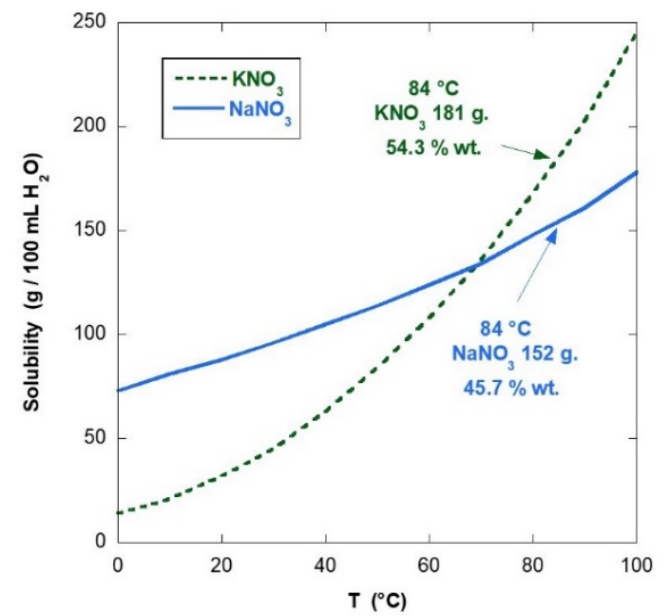

(a)

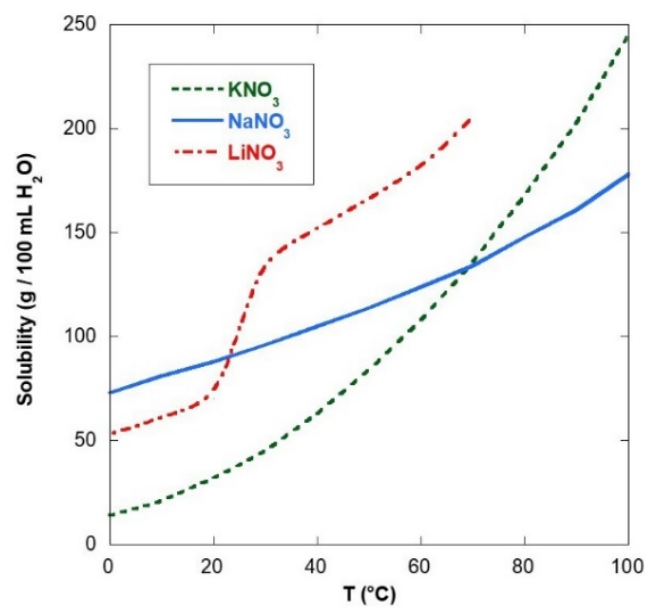

(b)

Figure 1. Solubility curves in water, at varying temperatures, of (a) KNO3 and NaNO3 and (b) LiNO3 compared to the other two salts.

\subsection{Preparation of Shape-Stabilized PCMs}

Generally, PCM stabilization was carried out by melting the salts and impregnating a porous medium with the molten salts [29,51]. Although effective, this method requires a high energy consumption to bring the PCM to melt and phenomena involving the release of salts by leakage can occur.

In this work the shape stabilization of the PCM was carried out by suitably impregnating the porous media with the saline solution then removing the solvent (DIW). This method exploits the advantage offered by the synthesis of salts in the solvent. In other studies, impregnation of PCMs in a humid environment has been found to be more effective in ensuring stable encapsulation of PCMs [53]. The saline solution prepared in LAC was gradually poured onto the suitably dried porous medium inside a vacuum oven. During the impregnation and subsequent drying, the temperature inside the oven was set at $84^{\circ} \mathrm{C}$ and $65{ }^{\circ} \mathrm{C}$ for the EUT and LiNaK-based SSPCMs respectively. The pressure of the vacuum oven was kept at $0.2 \mathrm{MPa}$ to minimize the capillary tension inside the cavities of the porous media and facilitate the penetration of the saline solution during wetting/drying processes, improving the impregnation efficiency. At the end of the $24 \mathrm{~h}$ of the drying cycle, the SSPCMs were dry, uniform and compact. The list of SSPCMs is summarized in Table 2.

Table 2. List of samples with content and type of SS and PCM.

\begin{tabular}{ccccc}
\hline Sample & Shape Stabilizer & $\begin{array}{c}\text { SS } \\
\text { \% wt. }\end{array}$ & $\begin{array}{c}\text { Phase Change } \\
\text { Material }\end{array}$ & $\begin{array}{c}\text { PCM } \\
\text { \% wt. }\end{array}$ \\
\hline 20A35 & CIMSIL A35 & 20 & EUT & 80 \\
15A35 & CIMSIL A35 & 15 & EUT & 85 \\
20DIA2 & DIA2 & 20 & EUT & 80 \\
15DIA2 & DIA2 & 15 & EUT & 85 \\
20A55 & CIMSIL A55 & 20 & EUT & 80 \\
20ATZ70 & ATZ70 & 20 & EUT & 80 \\
LiNaK_20DIA2 & DIA2 & 20 & LiNaK & 80 \\
LiNaK_20A35 & CIMSIL A35 & 20 & LiNaK & 80 \\
\hline
\end{tabular}




\subsection{Methods of Characterization}

The morphological characterization of shape-stabilizers and SSPCM was performed with a field emission scanning electron microscope (FESEM) Supra 25 by Zeiss (Oberkochen, Germany). Micrographs were performed with an accelerating voltage of $2.5 \mathrm{kV}$ at different magnifications. Previously, the samples were sputtered with gold to provide good electrical conductivity.

The thermal degradation of the SS was verified with a thermo-gravimetric analyzer (TGA) -Exstar 6300 by Seiko Instruments (Chiba, Japan) by evaluating the TG weight loss as a function of temperature. The tests were performed in a dynamic temperature regime with a $10^{\circ} \mathrm{C} / \mathrm{min}$ ramp from 30 to $900^{\circ} \mathrm{C}$ in an inert atmosphere $\left(\mathrm{N}_{2}\right)$. The thermograms of the TGA curves and their derivatives (DTG) provide information on the thermal stability of the materials as the temperature rises.

The calorimetric behavior of the samples produced was studied with a differential scanning calorimeter (DSC) Q200 (TA Instrument, New Castle, DE, US). Samples of approximately $20 \mathrm{mg}$, previously dried in a vacuum oven for $24 \mathrm{~h}$ at $105^{\circ} \mathrm{C}$ at $0.2 \mathrm{MPa}$, were analyzed in inert atmosphere $\left(\mathrm{N}_{2}\right.$ flow $\left.50 \mathrm{~mL} / \mathrm{min}\right)$. The samples were subjected to two heating and cooling cycles between -10 and $360^{\circ} \mathrm{C}$ with a rate of $10^{\circ} \mathrm{C} / \mathrm{min}$. The results of the DSC analysis have been reported in the form of temperature/heat flow curves, calculating transformation enthalpies and characteristic temperatures.

\section{Results and Discussion}

\subsection{Characterization of the Shape Stabilizers}

\subsubsection{Morphology}

The different morphology of the selected porous media was studied with a FESEM Supra 25 operating with voltages of $2.5 \mathrm{kV}$ with magnifications ranging from $100 \times$ to $50,000 \times$. The most significant and characterizing images of the SS at $5000 \times$ and $25,000 \times$ magnifications are shown in Figure 2. For DIA2 it was preferred to report the 10,000 $\times$ image instead of $25,000 \times$ as it is more representative of diatomite morphology.

CIMSIL A35 appears as a heterogeneous particulate consisting of conglomerates of micrometric size ranging from a few units to a few tens of micrometers. At $5000 \times$ magnification we begin to distinguish the acicular structure of the sepiolite which constitutes the microconglomerates. At 25,000 $\times$ the nanometric needles are clearly distinguished, consisting of the characteristic hollow quincunx structures of silicates $[55,56]$.

The morphology of the DIA2 diatomite shows a wide heterogeneity, due to its fossil origin, with multiple structures characterized by porosity and cavity [26,39]. The size distribution is wide, although the prevailing particle size is a few units of a micrometer. At $10,000 \times$ magnification you can see the detail of a porous cylindrical structure that appears particularly functional for the encapsulation of PCM.

CIMSIL A55 appears as a particle aggregate some tens of micrometers in size. At $25,000 \times$ the fibrillar structure of the sepiolite can be seen with nanometric sections and a not particularly high aspect ratio. Compared to CIMSIL A35, the sepiolitic/palygorskitic structures are coarser and more aggregated, justifying the greater density of the A55 compared to the A35 [47,57].

The micrographs of the ATZ70 zeolite highlight the dimensional heterogeneity of the particles which varies from sub-micrometric to a few tens of micrometers. At higher magnifications, the crystalline geometry structure typical of minerals of volcanic origin (phillipsite and chabazite) belonging to the class of tectosilicates is highlighted. In particular, the mineralogical structure of ATZ70 consists of a three-dimensional framework of $\mathrm{SiO}_{4}{ }^{4-}$ tetrahedra (with partial replacement of $\mathrm{Si}^{4+}$ with $\mathrm{Al}^{3+}$ ) of hydrated aluminosilicates of $\mathrm{Na}$, $\mathrm{K}, \mathrm{Ca}, \mathrm{Mg}$. This structure is characterized by the presence of channels and cavities in which ions and extra framework polar molecules find accommodation, endowed with extreme mobility, conferring relevant attitude to the hydration-dehydration phenomenon [58,59]. 


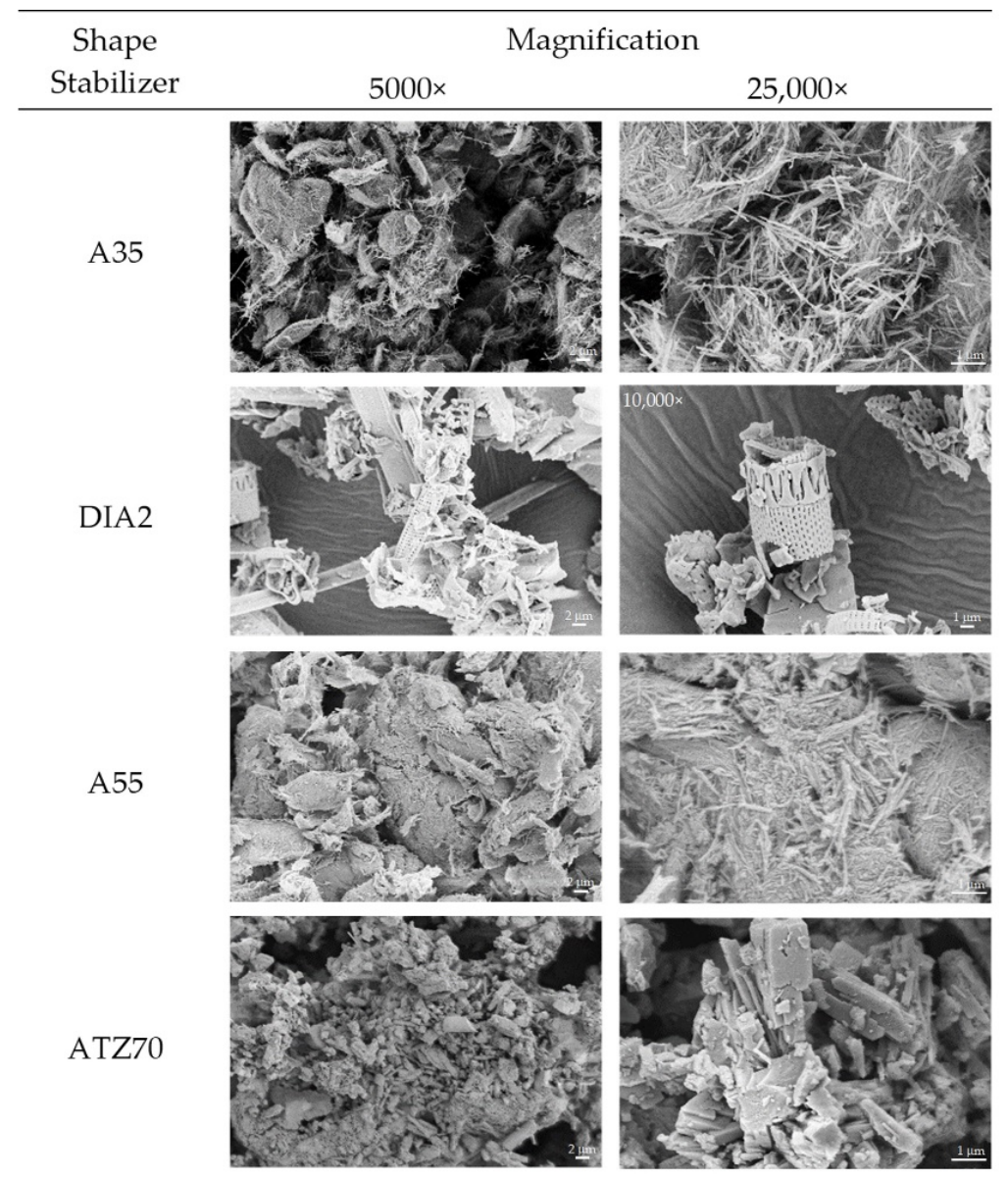

Figure 2. SEM micrographs of the porous media selected for the shape stabilization of the PCM.

\subsubsection{Thermal Stability}

The results of the thermo-degradation tests were reported in the form of TG/T curves, calculating the derivatives (DTG) and reporting them in a graph. In Figure 3, the TG/DTG graphs of the selected shape stabilizers.

All the selected shape stabilizers showed good thermal stability in the temperature range $\left(30-600{ }^{\circ} \mathrm{C}\right)$ typical for the use of solar energy.

In general, the weight loss of sepiolites is mainly attributable to the loss of water that occurs in several stages during heating. First the absorbed water and a part of zeolite water $\left(\mathrm{T} 1<130{ }^{\circ} \mathrm{C}\right)$ are lost, then the second part of zeolitic water $\left(\mathrm{T} 1<\mathrm{T} 2<340{ }^{\circ} \mathrm{C}\right)$; subsequently, in two successive steps the bound water is lost $\left(\mathrm{T} 2<\mathrm{T} 3-\mathrm{T} 4<710^{\circ} \mathrm{C}\right)$ and finally dehydroxylation takes place [60-62]. For the two sepiolites used, in the first part of the curve $\left(\mathrm{T}<125^{\circ} \mathrm{C}\right.$ ) the loss of water is observed quantitatively in line with the values found in literature (8-9\% wt.). Sepiolite A35 shows a further slight weight loss around $276^{\circ} \mathrm{C}$ due to the separation of the zeolitic water molecules. Sepiolite/palygorskite A55 shows a slight weight loss referable to zeolitic water around $296{ }^{\circ} \mathrm{C}$, a temperature $20{ }^{\circ} \mathrm{C}$ higher than the other sepiolite due to the different particle morphology. The loss of bound water occurs between 340 and $675^{\circ} \mathrm{C}$ for $\mathrm{A} 35$ and between 355 and $710^{\circ} \mathrm{C}$ for $\mathrm{A} 55$, together with other thermodegradative phenomena such as the calcination of dolomite $\left(\mathrm{T}>600{ }^{\circ} \mathrm{C}\right)$. At $815^{\circ} \mathrm{C}$, the dehydroxylation peak occurs for both sepiolites.

DIA2 diatomite, although calcined, shows a very slight weight loss (1.8\% wt.) in two steps: it loses the residues of absorbed water and zeolite water showing a DTG peak at $165^{\circ} \mathrm{C}$ and another DTG peak around $293^{\circ} \mathrm{C}$, also attributable to the loss of structural water residues [62-64]. 

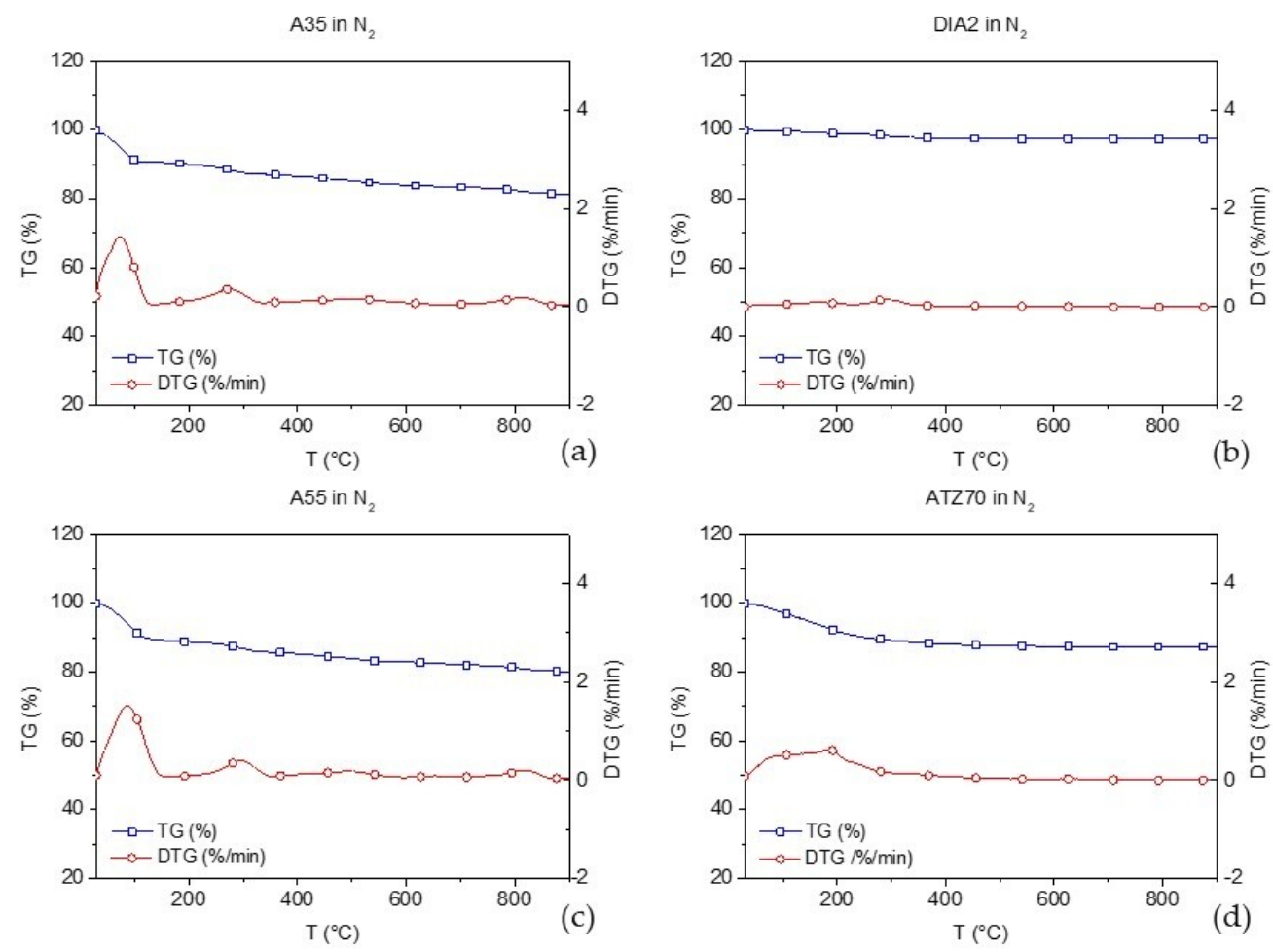

Figure 3. TG/DTG curves of the selected porous media: (a) Sepiolite A35, (b) Diatomite DIA2, (c) Sepiolite/Paligorskite A55 and (d) Zeolite ATZ70.

The ATZ70 shows a low temperature hygroscopic water loss peak $\left(\mathrm{T}<125^{\circ} \mathrm{C}\right)$ which is superimposed on the progressive loss of loosely bound zeolite water connected to the other peak around $186^{\circ} \mathrm{C}$ of zeolite water loss characteristic of these hydrated aluminosilicates. At higher temperatures, the tightly bound zeolite water is lost through a slow desorption mechanism $[58,64]$.

In general, all materials do not show significant weight losses attributable to thermal degradation in the temperature range of use $\left(\mathrm{T}<450{ }^{\circ} \mathrm{C}\right)$, so they are compatible with use as porous materials for the stabilization of PCM.

\subsection{Characterization of the Shape-Stabilized Phase Change Materials SSPCM}

The characterization of the shape-stabilized materials was carried out considering the calorimetric curves obtained with the thermal cycles of the DSC scans and relating to the morphology of the FESEM images carried out on the SSPCM samples. Previous work on PCM encapsulation with the molten salt method reported an upper limit of approximately $80 \%$ wt. of salts shape-stabilized with diatomite [29]. Starting with this data, the formulations of this study were produced with the aim of achieving the same result, but with convenient methods in terms of energy and process. Therefore, four cheap shape stabilizers (A35, DIA2, A55 and ATZ70) were used to produce materials that stably contained $80 \%$ PCM. Furthermore, for potentially more suitable materials, an attempt was made to increase the content of molten salts to $85 \% \mathrm{wt}$. to improve thermal storage performance. The storage capacity was evaluated by measuring the latent heat of phase transformation as the enthalpy of the main melting peak, considering that it is reasonable to assume the return of an equivalent heat of crystallization.

\subsubsection{DSC Results}

The calorimetric values of the eutectic mixture of potassium and sodium nitrate salts of Table 3 show that the average temperature of the melting peak in the heating phase is $226{ }^{\circ} \mathrm{C}$ and that the melting enthalpy $\left(\Delta \mathrm{H}_{\mathrm{m}}\right)$ normalized to the mass is $97.7 \mathrm{~J} / \mathrm{g}$; in cooling, the average temperature of the crystallization peak is $218^{\circ} \mathrm{C}$ and the enthalpy of 
solidification $\left(\Delta \mathrm{H}_{\mathrm{C}}\right)$ is $96.9 \mathrm{~J} / \mathrm{g}$. Both peak temperatures and phase change energies are fully within the range of values reported in the literature [65]. An evaluation of the effectiveness of the stabilization of the PCM by SS can be obtained by comparing the enthalpy variation with the amount of PCM present in the SSPCM. If the proportion between the content of PCM and DH is respected, then a complete and effective encapsulation has been achieved; for example, if the PCM content is $80 \%$ wt., an enthalpy value equal to $80 \%$ of that measured on the PCM should be obtained to consider the stabilization completely effective. If the shape stabilization coefficient $\left(\mathrm{SS}_{\mathrm{C}}\right)$ is defined as the ratio between the enthalpy variations $(\triangle \mathrm{H})$, of the SSPCM and of the PCM, normalized to the fraction of PCM contained in the shape-stabilized material, as reported in Equation (1).

$$
\text { Shape Stabilization coefficient } \mathrm{SS}_{\mathrm{C}}(\%)=\frac{\Delta \mathrm{H}_{\mathrm{SSPCM}}}{\mathrm{X}_{\mathrm{SSPCM}}^{\mathrm{PCM}} * \Delta \mathrm{H}_{\mathrm{PCM}}} \mathrm{X} 100
$$

where $\Delta \mathrm{H}_{\mathrm{SSPCM}}$ is the phase change enthalpy of the SSPCM, $\Delta \mathrm{H}_{\mathrm{PCM}}$ is the phase change enthalpy of the PCM only, $\mathrm{X}_{\mathrm{SSPCM}}^{\mathrm{PCM}}$ is the fraction by weight of nominal PCM of the SSPCM formulation.

Table 3. Thermal characteristics of the SSPCM (EUT-based) obtained from the analysis by differential scanning calorimeter on the 2nd heating/cooling cycle.

\begin{tabular}{ccccccccc}
\hline Sample & $\begin{array}{c}\text { Shape } \\
\text { Stabilizer }\end{array}$ & $\begin{array}{c}\text { SS } \\
\text { \% wt. }\end{array}$ & $\begin{array}{c}\mathbf{P C M} \\
\mathbf{\%} \mathbf{w t} .\end{array}$ & $\begin{array}{c}\mathbf{T}_{\mathbf{m}} \\
{ }^{\circ} \mathbf{C}\end{array}$ & $\begin{array}{c}\Delta \mathbf{H}_{\mathbf{m}} \\
\mathbf{J} / \mathbf{g}\end{array}$ & $\begin{array}{c}\mathbf{S S}_{\mathbf{c}} \\
\mathbf{\%}\end{array}$ & $\begin{array}{c}\mathbf{T}_{\mathbf{c}} \\
\mathbf{W} / \mathbf{g}\end{array}$ & $\begin{array}{c}\mathbf{\Delta} \mathbf{H}_{\mathbf{c}} \\
\mathbf{J} / \mathbf{g}{ }^{\circ} \mathbf{C}\end{array}$ \\
\hline EUT & - & - & 100 & $226 \pm 1$ & $97.7 \pm 2.4$ & - & $218 \pm 1$ & $96.9 \pm 2.1$ \\
20A35 & CIMSIL A35 & 20 & 80 & $220 \pm 1$ & $48.7 \pm 4.3$ & 62.3 & $218 \pm 1$ & $49.0 \pm 3.8$ \\
15A35 & CIMSIL A35 & 15 & 85 & $224 \pm 2$ & $57.6 \pm 8.2$ & 69.4 & $216 \pm 3$ & $57.7 \pm 5.8$ \\
20DIA2 & DIA2 & 20 & 80 & $232 \pm 2$ & $77.9 \pm 2.3$ & 99.7 & $211 \pm 2$ & $77.6 \pm 1.9$ \\
15DIA2 & DIA2 & 15 & 85 & $228 \pm 3$ & $77.7 \pm 6.1$ & 93.6 & $210 \pm 3$ & $77.9 \pm 6.4$ \\
20A55 & CIMSIL A55 & 20 & 80 & $224 \pm 1$ & $47.5 \pm 4.6$ & 60.8 & $219 \pm 1$ & $51.2 \pm 5.3$ \\
20ATZ70 & ATZ70 & 20 & 80 & $221 \pm 1$ & $68.2 \pm 2.2$ & 87.3 & $215 \pm 2$ & $69.4 \pm 2.6$ \\
\hline
\end{tabular}

In Table 3, it can be seen that $\mathrm{SS}_{\mathrm{c}}$ of $20 \mathrm{~A} 35$ is $62.3 \%$, which is indicative of a not entirely effective stabilization. If we observe the $\mathrm{SS}_{\mathrm{c}}$ values calculated for all shape-stabilized PCM EUT-based, we note that 20DIA2 reaches a value close to $100 \%$ which constitutes the complete stabilization of the PCM. When PCM content is increased to $85 \%$ wt., as in 15DIA2, the $\mathrm{SS}_{\mathrm{c}}$ value decreases while the absolute value of the enthalpy is equivalent (77.7-77.9 J/g) between the 20DIA2 and 15DIA2 samples; this result leads to the conclusion that the absorption limit of the DIA2 for the PCM is just $80 \%$ wt. Sample 20A55 shows the worst result both in terms of $\mathrm{SS}_{\mathrm{c}}$ index and absolute enthalpy value, resulting in the least effective shape stabilizer of the selected SS set. The ATZ70 zeolite with 20\% wt. of PCM shows a good value of the stabilization coefficient (87.3\%) but still lower than those encapsulated with diatomite.

The shifts in the temperature of the melting peak can be interpreted in relation to the stability of the SSPCM as a good encapsulation delays the melting by raising the temperature (20DIA2, 15DIA2) while phenomena of loss of the PCM due to leakage favor the thermal conductivity on the DSC crucible by anticipating the merger. In a specular way, the results can also be found in cooling. In Figure 4, observing the shape of the DSC curves representative of the SSPCM produced, it can be seen that the less shape-stabilized samples (e.g., 20A55) show a deformation of the peak with initiation of melting at lower temperatures than the more stable ones (e.g., 20DIA2). This conformation is probably due to the presence of free salts, in contact but not bound by the shape stabilizers, which anticipate the melting. These considerations are also reflected in the following morphological study of SSPCM. 


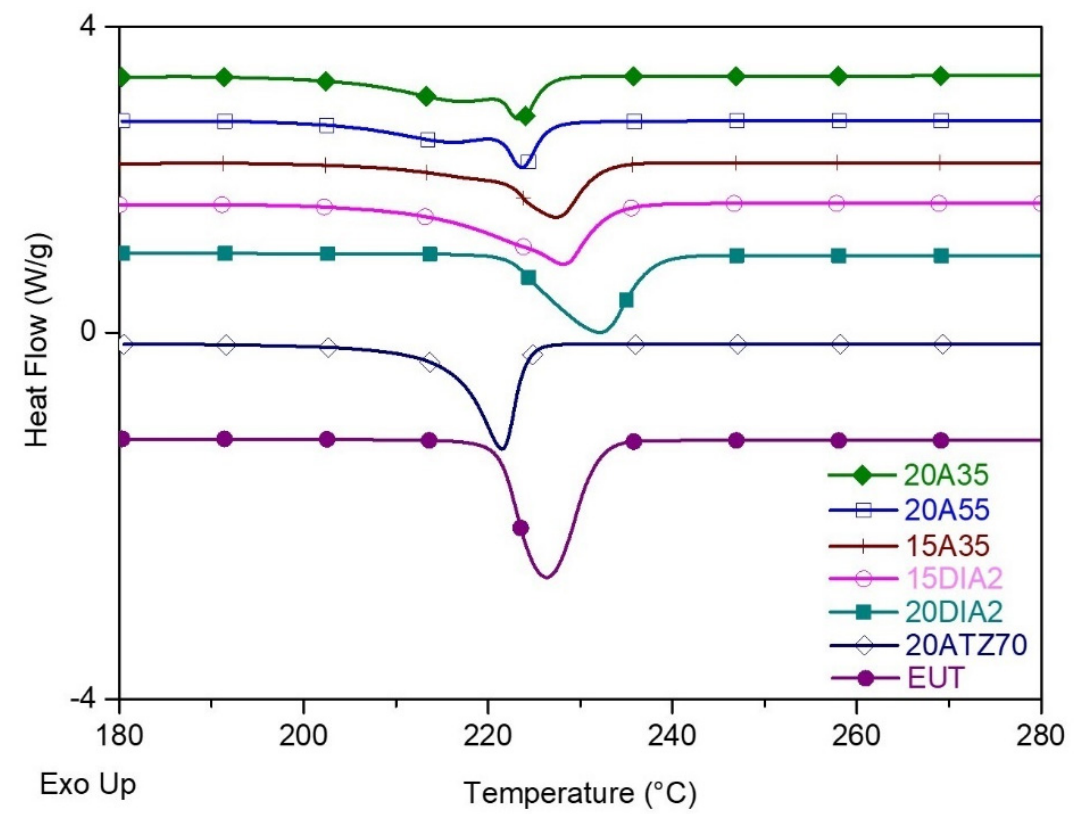

Figure 4. DSC curves around the melting peaks at the 2nd thermal cycle of the SSPCM samples.

In conclusion, the best stabilization is obtained with diatomite and the $80 \% \mathrm{wt}$. of PCM results in a maximum impregnation limit with an encapsulation coefficient of $99.7 \%$ for the SSPCM called 20DIA2.

Taking into account the results obtained with the EUT-based SSPCM, the formulations based on LiNak salts have been limited to the two most promising SS, namely A35 and DIA2 both at 20\% wt. The exclusion of A55 and ATZ70 were motivated respectively by the poor performance and by the early melting at low temperature, which would have compromised the thermal yield of LiNaK salts already operating at low temperatures $[66,67]$. While the ternary salt mixture displays the characteristic calorimetric values, both shape-stabilized PCMs show a phase transformation delay which manifests itself with an increase in melting temperature and a decrease in crystallization temperature [68,69]. This phenomenon is indicative of the successful stabilization of the PCM LiNaK-based by the porous media. To quantify the effectiveness of the encapsulation, the characteristic calorimetric parameters of the materials produced were reported (Table 4) and the shape stabilization coefficient $\mathrm{SS}_{\mathrm{c}}$ was calculated. It is noted that, even in the case of LiNaK salts, the stabilization effect conferred by the diatomite on the LiNaK_20DIA2 sample is almost complete, reaching a value of $97.7 \%$. It is interesting to note that with this PCM the CIMSIL A35 also improves, obtaining a high efficiency $(82.7 \%)$.

Table 4. DSC results at the 2nd heating/cooling cycle of the SSPCM (LiNaK-based) characterization.

\begin{tabular}{cccccccccc}
\hline Sample & $\begin{array}{c}\text { Shape } \\
\text { Stabilizer }\end{array}$ & $\begin{array}{c}\text { SS } \\
\mathbf{\%} \mathbf{w t}\end{array}$ & $\begin{array}{c}\mathbf{P C M} \\
\mathbf{\%} \mathbf{w t}\end{array}$ & $\begin{array}{c}\mathbf{T}_{\mathbf{m}} \\
{ }^{\circ} \mathbf{C}\end{array}$ & $\begin{array}{c}\boldsymbol{\Delta} \mathbf{H}_{\mathbf{m}} \\
\mathbf{J} / \mathbf{g}\end{array}$ & $\begin{array}{c}\mathbf{S S}_{\mathbf{c}} \\
\mathbf{\%}\end{array}$ & $\begin{array}{c}\mathbf{T}_{\mathbf{c}} \\
\mathbf{W} / \mathbf{g}\end{array}$ & $\begin{array}{c}\Delta \mathbf{H}_{\mathbf{c}} \\
\mathbf{J} / \mathbf{g}{ }^{\circ} \mathbf{C}\end{array}$ & $\begin{array}{c}\mathbf{S S}_{\mathbf{c c}} \\
\mathbf{\%}\end{array}$ \\
\hline LiNaK & - & - & 100 & $129 \pm 1$ & $142.5 \pm 2$ & - & $92 \pm 1$ & $117.5 \pm 2$ \\
LiNaK_20DIA2 & DIA2 & 20 & 80 & $135 \pm 1$ & $111.4 \pm 3$ & 97.7 & $85 \pm 1$ & $94.0 \pm 2$ & 100 \\
LiNaK_20A35 & CIMSIL A35 & 20 & 80 & $134 \pm 2$ & $94.3 \pm 3$ & 82.7 & $80 \pm 2$ & $93.8 \pm 2$ & 99.8 \\
\hline
\end{tabular}

During the cooling phase, the calculation is complicated by the crystallization phenomena which form shoulder peaks (Figure 5); however, if we consider the linear integration for the calculation of crystallization enthalpies, we obtain shape stabilization coefficient in cooling $\left(\mathrm{SS}_{\mathrm{cc}} \%\right)$ values which indicate a perfect encapsulation at the 2 nd heating. 


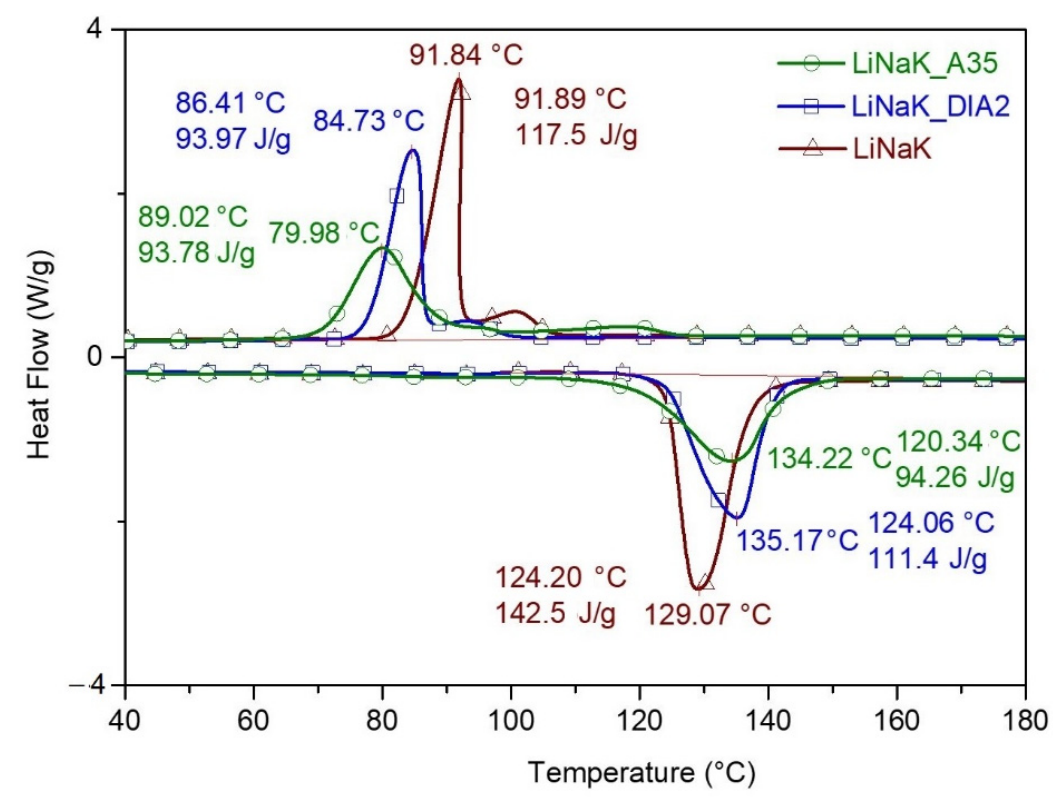

Figure 5. DSC curves of LiNaK salts and SSPCM based on DIA2 and A35 around the phase transition peaks at the 2nd heating/cooling cycle.

\subsubsection{Morphology of SSPCM}

In Figure 6, the FESEM images of the samples EUT-based with 20\% wt. of shape stabilizers made at 5, 10 and 25 thousand magnifications. The morphology of the shapestabilized PCM provides important information, also in relation to the results of the DSC thermal characterization. Furthermore, SEM micrographs contribute to the understanding of the stabilizing mechanism with which the different shape stabilizers act. Recalling the microscopies of the SS only (Figure 2), it is possible to distinguish the effect of impregnation of the salts on the absorbent particles.

Micrographs of 20A35 show a compact surface in which the acicular structures of the sepiolite are well interfaced and connected to the PCM. The structure is similar to a fiber-reinforced composite in which some agglomerates of fibers (sepiolite needles) and some matrix phase islands (molten salts) appear. It can be deduced that there is good compatibility between SS and PCM, but the dispersion of the porous medium was not entirely effective. This result may be due to the lack of solvent in the saline solution. In fact, the manufacturer of CIMSIL A35 recommends dispersion with over $90 \%$ of solvent; however, this quantity of DIW could not be used in order not to risk the selective precipitation of the salts in the vacuum drying phase of the SSPCM. It can be hypothesized that other porous media with a structure similar to sepiolite (e.g., attapulgite), but with different dispersion dynamics, could provide interesting results.

The 20DIA2 highlights the complete filling of the diatomite cavities with the PCM forming a compact and well bonded composite surface. It is deduced that higher quantities of salts cannot be absorbed by this porous medium and, not being shape-stabilized by encapsulation, would be lost due to leakage, without contributing to the storage of latent heat. This consideration is confirmed in the result of the calorimetric analysis of 15DIA2.

The morphology of SSPCM with A55 is similar to the shape-stabilized with sepiolite A35, with the difference that the structures of CIMSIL A55 appear coarser offering a smaller interaction surface with the PCM matrix phase. This consideration explains the lower encapsulation capacity of the EUT salts, and therefore of energy storage performance, of 20A55 compared to 20A35. It can be deduced that a decrease in the size of the fibers of the porous medium could lead to an increase in the stabilization capacity of the PCM with improved thermal storage performance; in this perspective, other porous media with a fibrous/acicular morphology such as attapulgite or halloysite nanotubes could be considered in the future. 


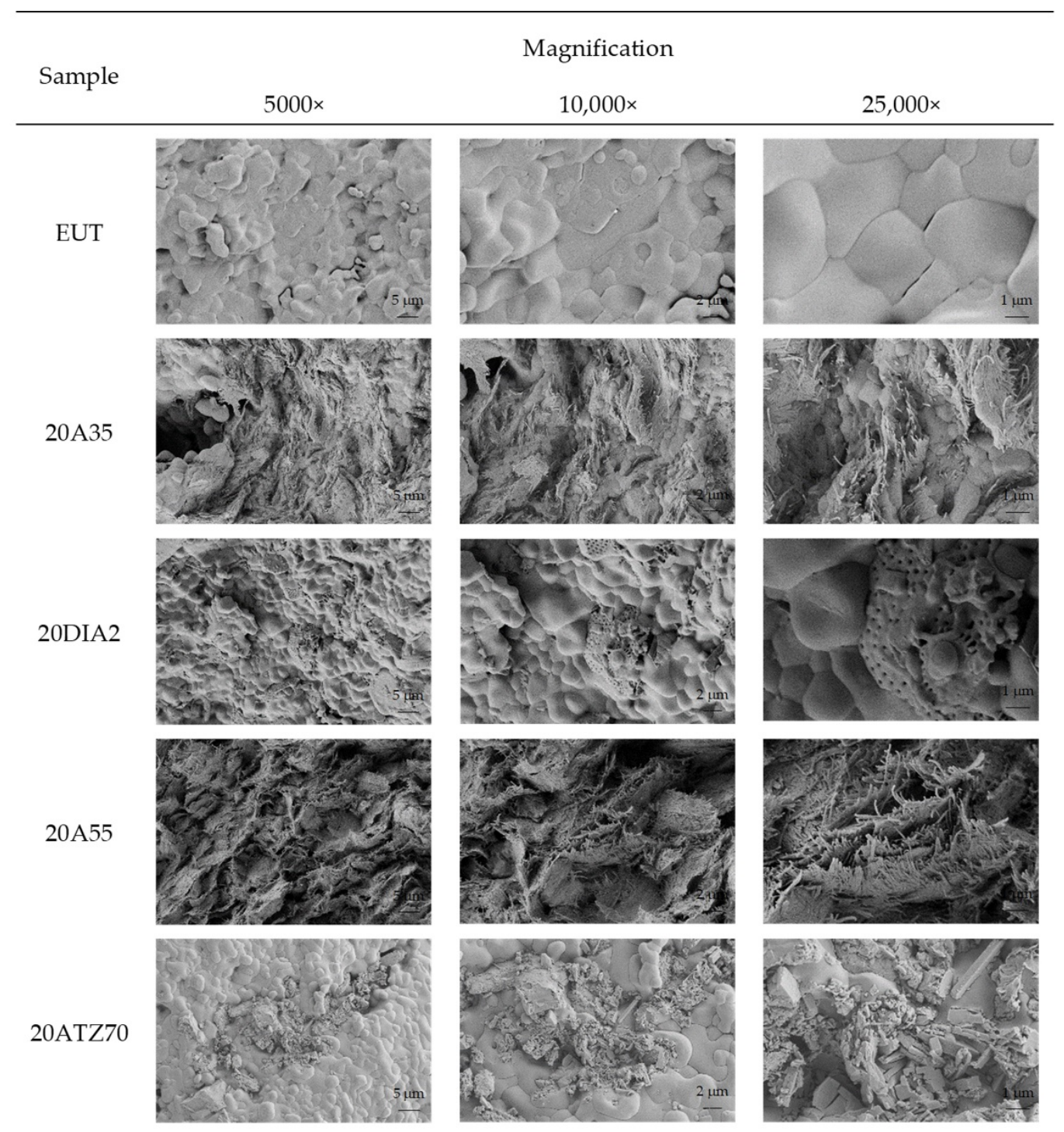

Figure 6. SEM micrographs of SSPCM (EUT-based) shape-stabilized with 20\% wt. of porous media.

Sample 20ATZ70 highlights some conglomerates of heterogeneous size of zeolite within the PCM phase. The dimensional non-uniformity of this material appears to be a limit for the uniform dispersion and effective stabilization of the PCM. In addition, the crystalline structure of the constituent zeolite minerals (phillipsite and chabazite) increases the density of ATZ70 so that, at the same weight with the other porous media, it offers a smaller total surface area of interaction with the salts. In the case of this stabilizing medium for PCM, size reduction and selection would be useful, but unfortunately, they are currently not available in the building materials market where ATZ70 was found. Furthermore, it would be useful to carry out a recalculation of the proportions between PCM and zeolite PM by reasoning in terms of volumes and contact surfaces rather than in mass. In conclusion, the results of the morphological analysis agree with the values of the calorimetric analysis, identifying the 20DIA2 sample as the best SSPCM.

In Figure 7, the morphological analysis carried out on LiNaK salts and SSPCM samples for medium temperatures confirms and supports the results obtained with DSC calorimetric analysis. The LiNaK salts show a smooth surface in which darker islands appear, probably referable to the presence of lithium [70]. At higher magnifications, crystal structures with random growth can be seen and the differences with respect to EUT salts are evident. The LiNaK_20DIA2 sample shows a compact surface in which the diatomite particles appear completely impregnated with LiNaK. At 25,000×, it is seen that the tubular diatomite 
structure is well bonded externally and filled in the cavity with the PCM phase. Since all the PCM portion used to make the SSPCM is shape-stabilized, there are no substantial losses due to leakage and the latent heat storage capacity is optimized. The micrographs of the LiNaK_20A35 sample show an effective random dispersion of the acicular structures within the $\mathrm{LiNaK}$ salts. The morphology of this sample explains the reason for the good value of the encapsulation coefficient obtained with the thermal characterization. In fact, the impregnation of the LiNaK_20A35 sample is improved compared to the corresponding 20A35 which used the salts for medium temperatures, indicating that the effectiveness of the stabilization also depends on the characteristics of the PCM used.

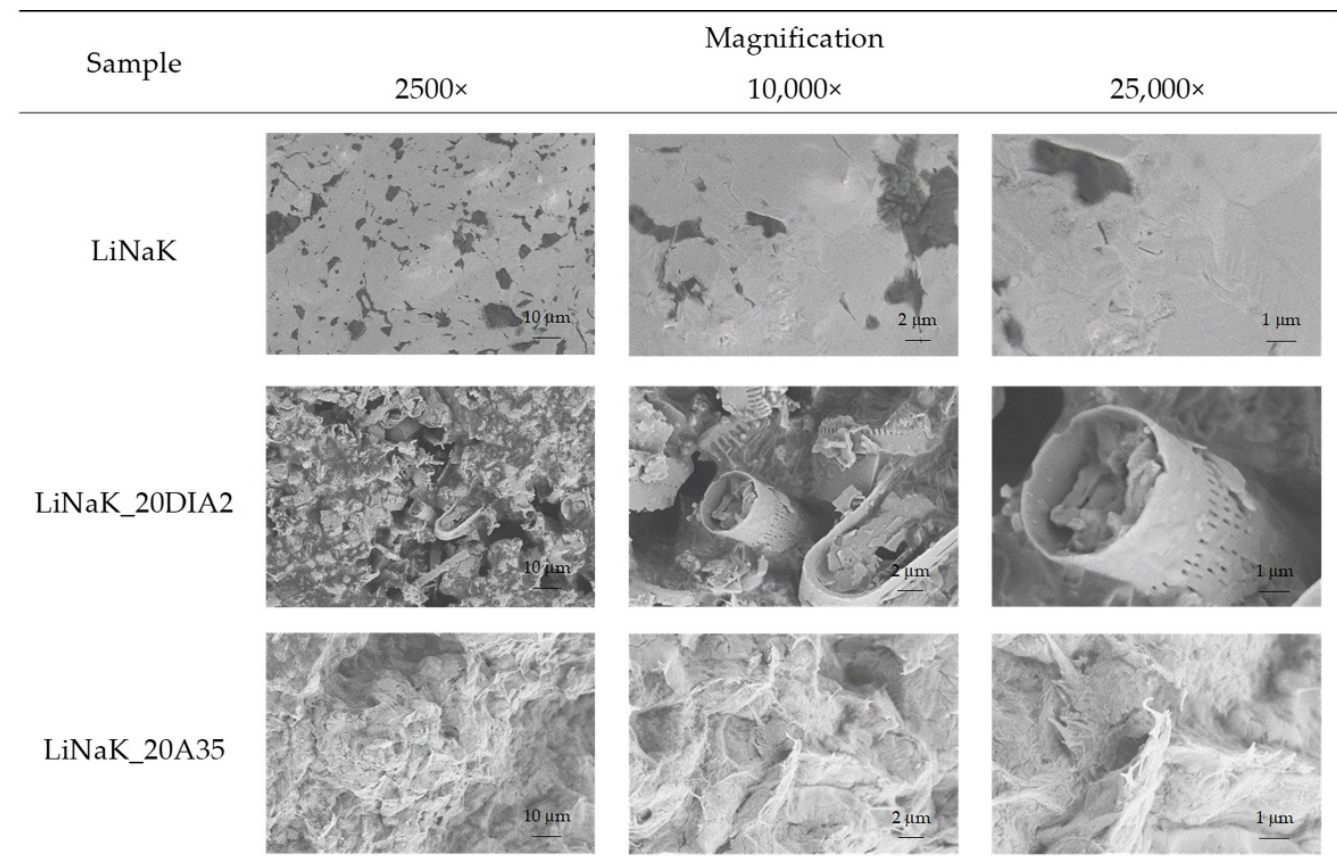

Figure 7. FESEM micrographs of LiNaK salts and its SSPCM produced with $20 \%$ wt. of DIA2 and A35.

\section{Conclusions}

This work aimed to study innovative materials for TES that could improve the exploitation of solar thermal energy in the direction of environmental sustainability. The shape stabilization of the phase change materials allows to conserve and appropriately use the latent heat of transformation, expanding their range of application.

Four cost-effective materials (sepiolite, diatomite, palygorskite and zeolite) from mining were selected as structural shape stabilizers. Thermal characterization demonstrated that all materials possessed good stability over the temperature range of the TES applications. The morphology of all the SS, observed by SEM, appeared to be suitable for the containment of PCM after transformation into the liquid phase.

Two PCMs were used-a three-component mixture of lithium, sodium and potassium nitrates in weight proportions 30:20:50 (LiNaK) for medium temperature applications and a eutectic mixture (EUT) of potassium and sodium nitrates for higher temperature ranges.

For the production of shapes-stabilized PCM, an innovative synthesis method with wet impregnation and in vacuum conditions has been devised to optimize the stabilization coefficient $\mathrm{SS}_{\mathrm{c}}$. The water assisted approach has shown efficacy, also producing a reduction in process energy consumption estimated at around $40 \%$ compared to the melt mixing method. The low pressure of the vacuum system has improved the filling of the porosities allowing to reach a PCM: SS weight ratio of 4:1 with a maximum filling coefficient equal to $97.7 \%$ for the 20DIA2 mixture. Zeolite also showed interesting results reaching a good SSc value (87.3\%) with a weight ratio of PCM: SS close to 3.5:1. Sepiolite showed mediocre results not exceeding $62 \%$ of shape stabilization with EUT salt; however, sepiolite A35 with 
LiNaK blend increased shape stabilization over $82 \%$ with a PCM: SS weight ratio greater than 3.2:1.

In conclusion, all samples produced showed PCM shape stabilization properties. The effectiveness of the shape stabilization process also depends on the method of synthesis of the SSPCM. The method adopted in this liquid assisted and vacuum dried work offers advantages both in terms of stabilization effectiveness and in terms of energy saving of the SSPCM production process. In the case of DIA2 diatomite, complete stabilization is achieved with both PCM for MT and HT.

Other factors, such as the chemical-physical affinity between SS and PCM and morphological characteristics such as size and porosity, affect the effectiveness of the stabilization. In the case of sepiolite A35, good results are obtained with PCM for MT but not as good with salts for HT.

Although this study highlighted the possibility of using these materials, which exploit the latent heat of PCMs, in applications where it is necessary to avoid the problems associated with leakage (HSMs immersed in gas and added in a solid matrix), limitations may also be encountered. These limits are related to the volumes occupied by SSPCMs which can reduce the functionality of the TES. For example, their addition to a cement matrix should be optimized to avoid the excessive reduction of the thermomechanical properties of the composite, as highlighted by Miliozzi et al. [30].

In the future it will be useful to investigate further factors that influence shape stabilization, while also considering other shape stabilizers and phase change materials in order to build a functional database for the formulation of SSPCM.

Author Contributions: Conceptualization, F.D. and A.M.; methodology, F.D.; validation, F.D. and L.T.; formal analysis, A.M.; investigation, A.M. and F.D.; writing-original draft preparation, review and editing, A.M. and F.D.; supervision, project administration, funding acquisition, L.T. All authors have read and agreed to the published version of the manuscript.

Funding: This research was funded by the Italian Ministry of Economic Development through the Research on Electric System—PTR 2019-21—Objective: Technologies—Project 1.2/WP2 (ThermalStorage).

Conflicts of Interest: The authors declare no conflict of interest. The funders had no role in the design of the study; in the collection, analyses, or interpretation of data; in the writing of the manuscript, or in the decision to publish the results.

\section{References}

1. OECD/IEA-International Energy Agency. World Energy Outlook. 2018. Available online: https://www.iea.org/topics/worldenergy-outlook (accessed on 15 September 2021).

2. IRENA. Scenarios for the Energy Transition: Global Experiences and Best Practices; International Renewable Energy Agency: Abu Dhabi, United Arab Emirates, 2020; ISBN 9789292602673.

3. International Renewable Energy Agency. Renewable Power Generation Costs in 2019. 2020. Available online: https://www.irena. org/ (accessed on 18 September 2021).

4. U.S. Energy Information Administration. International Energy Outlook 2019; 2019. Available online: https://www.eia.gov/ outlooks/ieo/ (accessed on 18 September 2021).

5. Sorrell, S. Reducing Energy Demand: A Review of Issues, Challenges and Approaches. Renew. Sustain. Energy Rev. 2015, 47, 74-82. [CrossRef]

6. Iddrisu, I.; Bhattacharyya, S.C. Sustainable Energy Development Index: A Multi-Dimensional Indicator for Measuring Sustainable Energy Development. Renew. Sustain. Energy Rev. 2015, 50, 513-530. [CrossRef]

7. Dargusch, M.; Liu, W.D.; Chen, Z.G. Thermoelectric Generators: Alternative Power Supply for Wearable Electrocardiographic Systems. Adv. Sci. 2020, 7, 2001362. [CrossRef] [PubMed]

8. Liu, W.D.; Wang, D.Z.; Liu, Q.; Zhou, W.; Shao, Z.; Chen, Z.G. High-Performance GeTe-Based Thermoelectrics: From Materials to Devices. Adv. Energy Mater. 2020, 10, 2000367. [CrossRef]

9. Liu, M.; Tay, N.S.; Bell, S.; Belusko, M.; Jacob, R.; Will, G.; Saman, W.; Bruno, F. Review on Concentrating Solar Power Plants and New Developments in High Temperature Thermal Energy Storage Technologies. Renew. Sustain. Energy Rev. 2016, 53, 1411-1432. [CrossRef]

10. Gajendiran, M.; Nallusamy, N. Application of Solar Thermal Energy Storage for Industrial Process Heating. Adv. Mater. Res. 2014, 984-985, 725-729. [CrossRef] 
11. Jacob, R.; Belusko, M.; Liu, M.; Saman, W.; Bruno, F. Using Renewables Coupled with Thermal Energy Storage to Reduce Natural Gas Consumption in Higher Temperature Commercial/Industrial Applications. Renew. Energy 2019, 131, 1035-1046. [CrossRef]

12. Sarbu, I.; Sebarchievici, C. A Comprehensive Review of Thermal Energy Storage. Sustainability 2018, 10, 191. [CrossRef]

13. Elbahjaoui, R.; el Qarnia, H. Performance Evaluation of a Solar Thermal Energy Storage System Using Nanoparticle-Enhanced Phase Change Material. Int. J. Hydrogen Energy 2019, 44, 2013-2028. [CrossRef]

14. Pirasaci, T.; Wickramaratne, C.; Moloney, F.; Goswami, D.Y.; Stefanakos, E. Influence of Design on Performance of a Latent Heat Storage System at High Temperatures. Appl. Energy 2018, 224, 220-229. [CrossRef]

15. Kenisarin, M.M. High-Temperature Phase Change Materials for Thermal Energy Storage. Renew. Sustain. Energy Rev. 2010, 14, 955-970. [CrossRef]

16. Cárdenas, B.; León, N. High Temperature Latent Heat Thermal Energy Storage: Phase Change Materials, Design Considerations and Performance Enhancement Techniques. Renew. Sustain. Energy Rev. 2013, 27, 724-737. [CrossRef]

17. Nomura, T.; Akiyama, T. High-temperature latent heat storage technology to utilize exergy of solar heat and industrial exhaust heat. In Green Energy and Technology; Springer: Berlin/Heidelberg, Germany, 2018; pp. 1207-1224.

18. Alam, T.E.; Dhau, J.S.; Goswami, D.Y.; Stefanakos, E. Macroencapsulation and Characterization of Phase Change Materials for Latent Heat Thermal Energy Storage Systems. Appl. Energy 2015, 154, 92-101. [CrossRef]

19. Zhang, F.; Zhong, Y.; Yang, X.; Lin, J.; Zhu, Z. Encapsulation of Metal-Based Phase Change Materials Using Ceramic Shells Prepared by Spouted Bed CVD Method. Sol. Energy Mater. Sol. Cells 2017, 170, 137-142. [CrossRef]

20. Wang, J.-W.; Zhang, C.-Z.; Li, Z.-H.; Zhou, H.-X.; He, J.-X.; Yu, J.-C. Corrosion Behavior of Nickel-Based Superalloys in Thermal Storage Medium of Molten Eutectic NaCl- $\mathrm{MgCl}_{2}$ in Atmosphere. Sol. Energy Mater. Sol. Cells 2017, 164, 146-155. [CrossRef]

21. Gomez-Vidal, J.C.; Tirawat, R. Corrosion of Alloys in a Chloride Molten Salt (NaCl-LiCl) for Solar Thermal Technologies. Sol. Energy Mater. Sol. Cells 2016, 157, 234-244. [CrossRef]

22. Milián, Y.E.; Gutiérrez, A.; Grágeda, M.; Ushak, S. A Review on Encapsulation Techniques for Inorganic Phase Change Materials and the Influence on Their Thermophysical Properties. Renew. Sustain. Energy Rev. 2017, 73, 983-999. [CrossRef]

23. Huang, X.; Chen, X.; Li, A.; Atinafu, D.; Gao, H.; Dong, W.; Wang, G. Shape-Stabilized Phase Change Materials Based on Porous Supports for Thermal Energy Storage Applications. Chem. Eng. J. 2019, 356, 641-661. [CrossRef]

24. Diao, Y.H.; Liang, L.; Zhao, Y.H.; Wang, Z.Y.; Bai, F.W. Numerical Investigation of the Thermal Performance Enhancement of Latent Heat Thermal Energy Storage Using Longitudinal Rectangular Fins and Flat Micro-Heat Pipe Arrays. Appl. Energy 2019, 233-234, 894-905. [CrossRef]

25. Jiang, F.; Zhang, L.; She, X.; Li, C.; Cang, D.; Liu, X.; Xuan, Y.; Ding, Y. Skeleton Materials for Shape-Stabilization of High Temperature Salts Based Phase Change Materials: A Critical Review. Renew. Sustain. Energy Rev. 2020, 119, 109539. [CrossRef]

26. Qian, T.; Li, J.; Min, X.; Deng, Y.; Guan, W.; Ning, L. Diatomite: A Promising Natural Candidate as Carrier Material for Low, Middle and High Temperature Phase Change Material. Energy Convers. Manag. 2015, 98, 34-45. [CrossRef]

27. Qin, Y.; Leng, G.; Yu, X.; Cao, H.; Qiao, G.; Dai, Y.; Zhang, Y.; Ding, Y. Sodium Sulfate-Diatomite Composite Materials for High Temperature Thermal Energy Storage. Powder Technol. 2015, 282, 37-42. [CrossRef]

28. Jiang, F.; Ge, Z.; Ling, X.; Cang, D.; Zhang, L.; Ding, Y. Improved Thermophysical Properties of Shape-Stabilized $\mathrm{NaNO}_{3} \mathrm{Using}$ Modified Diatomite-Based Porous Ceramic for Solar Thermal Energy Storage. Renew. Energy 2021, 179, 327-338. [CrossRef]

29. Miliozzi, A.; Chieruzzi, M.; Torre, L. Experimental Investigation of a Cementitious Heat Storage Medium Incorporating a Solar Salt/Diatomite Composite Phase Change Material. Appl. Energy 2019, 250, 1023-1035. [CrossRef]

30. Miliozzi, A.; Dominici, F.; Candelori, M.; Veca, E.; Liberatore, R.; Nicolini, D.; Torre, L. Development and Characterization of Concrete/PCM/Diatomite Composites for Thermal Energy Storage in CSP/CST Applications. Energies 2021, 14, 4410. [CrossRef]

31. Zalba, B.; Marın, J.M.; Cabeza, L.F.; Mehling, H. Review on Thermal Energy Storage with Phase Change: Materials, Heat Transfer Analysis and Applications. Appl. Therm. Eng. 2003, 23, 251-283. [CrossRef]

32. Yu, Q.; Jiang, Z.; Cong, L.; Lu, T.; Suleiman, B.; Leng, G.; Wu, Z.; Ding, Y.; Li, Y. A Novel Low-Temperature Fabrication Approach of Composite Phase Change Materials for High Temperature Thermal Energy Storage. Appl. Energy 2019, 237, 367-377. [CrossRef]

33. Zhang, P.; Xiao, X.; Ma, Z.W. A Review of the Composite Phase Change Materials: Fabrication, Characterization, Mathematical Modeling and Application to Performance Enhancement. Appl. Energy 2016, 165, 472-510. [CrossRef]

34. Huang, X.; Alva, G.; Jia, Y.; Fang, G. Morphological Characterization and Applications of Phase Change Materials in Thermal Energy Storage: A Review. Renew. Sustain. Energy Rev. 2017, 72, 128-145. [CrossRef]

35. Voronin, D.V.; Ivanov, E.; Gushchin, P.; Fakhrullin, R.; Vinokurov, V. Clay Composites for Thermal Energy Storage: A Review. Molecules 2020, 25, 1504. [CrossRef] [PubMed]

36. Zhang, S.; Feng, D.; Shi, L.; Wang, L.; Jin, Y.; Tian, L.; Li, Z.; Wang, G.; Zhao, L.; Yan, Y. A Review of Phase Change Heat Transfer in Shape-Stabilized Phase Change Materials (Ss-PCMs) Based on Porous Supports for Thermal Energy Storage. Renew. Sustain. Energy Rev. 2021, 135, 110127. [CrossRef]

37. Umair, M.M.; Zhang, Y.; Iqbal, K.; Zhang, S.; Tang, B. Novel Strategies and Supporting Materials Applied to Shape-Stabilize Organic Phase Change Materials for Thermal Energy Storage-A Review. Appl. Energy 2019, 235, 846-873. [CrossRef]

38. Xie, N.; Luo, J.; Li, Z.; Huang, Z.; Gao, X.; Fang, Y.; Zhang, Z. Salt Hydrate/Expanded Vermiculite Composite as a Form-Stable Phase Change Material for Building Energy Storage. Sol. Energy Mater. Sol. Cells 2019, 189, 33-42. [CrossRef]

39. Xu, B.; Li, Z. Paraffin/Diatomite Composite Phase Change Material Incorporated Cement-Based Composite for Thermal Energy Storage. Appl. Energy 2013, 105, 229-237. [CrossRef] 
40. Zhang, X.; Wen, R.; Tang, C.; Wu, B.; Huang, Z.; Min, X.; Huang, Y.; Liu, Y.; Fang, M.; Wu, X. Thermal Conductivity Enhancement of Polyethylene Glycol/Expanded Perlite with Carbon Layer for Heat Storage Application. Energy Build. 2016, 130, $113-121$. [CrossRef]

41. Liu, S.; Yang, H. Stearic Acid Hybridizing Coal-Series Kaolin Composite Phase Change Material for Thermal Energy Storage. Appl. Clay Sci. 2014, 101, 277-281. [CrossRef]

42. Lv, P.; Liu, C.; Rao, Z. Experiment Study on the Thermal Properties of Paraffin/Kaolin Thermal Energy Storage Form-Stable Phase Change Materials. Appl. Energy 2016, 182, 475-487. [CrossRef]

43. Ran, X.; Wang, H.; Zhong, Y.; Zhang, F.; Lin, J.; Zou, H.; Dai, Z.; An, B. Thermal Properties of Eutectic Salts/Ceramics/Expanded Graphite Composite Phase Change Materials for High-Temperature Thermal Energy Storage. Sol. Energy Mater. Sol. Cells 2021, 225. [CrossRef]

44. Sari, A.; Karaipekli, A. Thermal Conductivity and Latent Heat Thermal Energy Storage Characteristics of Paraffin/Expanded Graphite Composite as Phase Change Material. Appl. Therm. Eng. 2007, 27, 1271-1277. [CrossRef]

45. Li, X.; Sanjayan, J.G.; Wilson, J.L. Fabrication and Stability of Form-Stable Diatomite/Paraffin Phase Change Material Composites. Energy Build. 2014, 76, 284-294. [CrossRef]

46. Xu, G.; Leng, G.; Yang, C.; Qin, Y.; Wu, Y.; Chen, H.; Cong, L.; Ding, Y. Sodium Nitrate-Diatomite Composite Materials for Thermal Energy Storage. Sol. Energy 2017, 146, 494-502. [CrossRef]

47. Konuklu, Y.; Ersoy, O. Preparation and Characterization of Sepiolite-Based Phase Change Material Nanocomposites for Thermal Energy Storage. Appl. Therm. Eng. 2016, 107, 575-582. [CrossRef]

48. Wang, Y.; Song, Y.; Li, S.; Zhang, T.; Zhang, D.; Guo, P. Thermophysical Properties of Three-Dimensional Palygorskite Based Composite Phase Change Materials. Appl. Clay Sci. 2020, 184, 105367. [CrossRef]

49. Choi, J.; Valtchev, V.; Moteki, T.; Ogura, M. Phase Change Material-Containing Mesoporous Zeolite Composite for Adsorption Heat Recovery. Adv. Mater. Interfaces 2021, 8, 2001085. [CrossRef]

50. de Matos Degues, K.; Cypriano, M.G.; Coelho, K.B.; Luza, A.L.; Montedo, O.R.K.; de Castro, L.C.; Angioletto, E. Assessment of PCM-Impregnated Zeolite as a Matrix for Latent Heat Storage. Mater. Sci. Forum 2018, 912, 87-92. [CrossRef]

51. Deng, Y.; Li, J.; Qian, T.; Guan, W.; Wang, X. Preparation and Characterization of KNO3/Diatomite Shape-Stabilized Composite Phase Change Material for High Temperature Thermal Energy Storage. J. Mater. Sci. Technol. 2017, 33, 198-203. [CrossRef]

52. Jeong, S.G.; Jeon, J.; Lee, J.H.; Kim, S. Optimal Preparation of PCM/Diatomite Composites for Enhancing Thermal Properties. Int. J. Heat Mass Transf. 2013, 62, 711-717. [CrossRef]

53. Leng, G.; Qiao, G.; Jiang, Z.; Xu, G.; Qin, Y.; Chang, C.; Ding, Y. Micro Encapsulated \& Form-Stable Phase Change Materials for High Temperature Thermal Energy Storage. Appl. Energy 2018, 217, 212-220. [CrossRef]

54. Yin, X.; Yu, X.; Wu, X.; Fu, X.; Wu, H.; Zeng, D. Solubility Prediction and Measurement of the System $\mathrm{KNO}_{3}-\mathrm{LiNO}_{3}-\mathrm{NaNO}_{3}-\mathrm{H}_{2} \mathrm{O}$. J. Chem. Eng. Data 2013, 58, 1839-1844. [CrossRef]

55. Tartaglione, G.; Tabuani, D.; Camino, G. Thermal and Morphological Characterisation of Organically Modified Sepiolite. Microporous Mesoporous Mater. 2008, 107, 161-168. [CrossRef]

56. Lescano, L.; Castillo, L.; Marfil, S.; Barbosa, S.; Maiza, P. Alternative Methodologies for Sepiolite Defibering. Appl. Clay Sci. 2014, 95, 378-382. [CrossRef]

57. Tang, Q.; Wang, F.; Tang, M.; Liang, J.; Ren, C. Study on Pore Distribution and Formation Rule of Sepiolite Mineral Nanomaterials. J. Nanomater. 2012, 2012, 382603. [CrossRef]

58. de' Gennaro, R.; Cappelletti, P.; Cerri, G.; de' Gennaro, M.; Dondi, M.; Langella, A. Zeolitic Tuffs as Raw Materials for Lightweight Aggregates. Appl. Clay Sci. 2004, 25, 71-81. [CrossRef]

59. Rice, S.B. Transmission Electron Microscope Observations of Planar Defects in Ferrierite from Kamloops Lake, British Columbia. Am. Miner. 1995, 80, 930-936. [CrossRef]

60. Önal, M.; Yilmaz, H.; Sarikaya, Y. Some Physicochemical Properties of the White Sepiolite Known as Pipestone from Eskìşehìr, Turkey. Clays Clay Miner. 2008, 56, 511-519. [CrossRef]

61. Hojati, S.; Khademi, H. Thermal Behavior of a Natural Sepiolite from Northeastern Iran. J. Sci. Islamic Repub. Iran 2013, 24, 129-134.

62. Meradi, H.; Atoui, L.; Bahloul, L.; Boubendira, K.; Bouazdia, A.; Ismail, F. Characterization by Thermal Analysis of Natural Kieselguhr and Sand for Industrial Application. In Proceedings of the Energy Procedia, Beirut, Lebanon, 17-20 April 2015; Elsevier Ltd.: Amsterdam, The Netherlands, 2015; Volume 74, pp. 1282-1288. [CrossRef]

63. Meradi, H.; L'Hadi, A.; Ghabeche, W.; Bahloul, L. Contribution to Characterization of Natural Diatomite. In Proceedings of the International Conference on Water, Environment, Energy and Society ICWEES' 2018, Djerba Island, Tunisia, 8-11 May 2018. Available online: https:/ / www.icwees2018.tn (accessed on 22 September 2021).

64. Knowlton, G.D.; White, T.R.; Mckague, H.L. Thermal Study of Types of Water Associated with Clinoptilolite. Clays Clay Miner. 1981, 29, 403-411. [CrossRef]

65. Chieruzzi, M.; Cerritelli, G.F.; Miliozzi, A.; Kenny, J.M. Effect of Nanoparticles on Heat Capacity of Nanofluids Based on Molten Salts as PCM for Thermal Energy Storage. Nanoscale Res. Lett. 2013, 8, 448. [CrossRef] [PubMed]

66. Takahashi, Y.; Sakamoto, R.; Kamimoto, M. Heat Capacities and Latent Heats of $\mathrm{LiNO}_{3}, \mathrm{NaNO}_{3}$, and $\mathrm{KNO}_{3}$. Int. J. Thermophys. 1988, 9, 1081-1090. [CrossRef] 
67. Trujillo, U.; Rueckert, T.L.; Reddy, R.G.; United States Department of Energy. Novel Molten Salts Thermal Energy Storage for Concentrating Solar Power Generation. 2013. Available online: https://www.osti.gov/servlets/purl/1111584/ (accessed on 18 September 2021).

68. Coscia, K.; Nelle, S.; Elliott, T.; Mohapatra, S.; Oztekin, A.; Neti, S. Thermophysical Properties of $\mathrm{LiNO}_{3}-\mathrm{NaNO}_{3}-\mathrm{KNO}_{3} \mathrm{Mixtures}$ for Use in Concentrated Solar Power. J. Sol. Energy Eng. Trans. ASME 2013, 135, 034506. [CrossRef]

69. Bradshaw, R.W.; Meeker, D.E. High-Temperature Stability of Ternary Nitrate Molten Salts for Solar Thermal Energy Systems. Sol. Energy Mater. 1990, 21, 51-60. [CrossRef]

70. Wang, T.; Mantha, D.; Reddy, R.G. Thermal Stability of the Eutectic Composition in $\mathrm{LiNO}_{3}-\mathrm{NaNO}_{3}-\mathrm{KNO}_{3}$ Ternary System Used for Thermal Energy Storage. Sol. Energy Mater. Sol. Cells 2012, 100, 162-168. [CrossRef] 